\title{
Adjuvant Radiotherapy in Patients With Pancreatic Adenocarcinoma. Is It Still Appealing in Clinical Trials? A Meta-analysis and Review of the Literature
}

\author{
FRANCESCO PASQUALETTI ${ }^{1,2}$, ALDO SAINATO $^{2}$, RICCARDO MORGANTI $^{3}$, \\ CONCETTA LALISCIA ${ }^{2}$, ENRICO VASILE ${ }^{4}$, ALESSANDRA GONNELLI ${ }^{2}$, \\ SABRINA MONTRONE ${ }^{2}$, GIOVANNI GADDUCCI ${ }^{2}$, NOEMI GIANNINI ${ }^{2}$, NATALINA COCCIA ${ }^{2}$, \\ TAIUSHA FUENTES ${ }^{2}$, SOFIA ZANOTTI ${ }^{5}$, MASSIMO FALCONI ${ }^{* *}$ and FABIOLA PAIAR ${ }^{2 *}$ \\ ${ }^{1}$ Department of Oncology, University of Oxford, Oxford, U.K.; \\ ${ }^{2}$ Unit of Radiation Oncology, Pisa University Hospital, Pisa, Italy; \\ ${ }^{3}$ Unit of Section of Statistics, Department of Clinical and Experimental Medicine, University of Pisa, Pisa, Italy; \\ ${ }^{4}$ Unit of Medical Oncology, Pisa University Hospital, Pisa, Italy; \\ ${ }^{5}$ Anatomic Pathology Unit, IRCCS Humanitas University Research Hospital, Milan, Italy; \\ ${ }^{6}$ Division of Pancreatic Surgery, Department of Surgery, IRCCS San Raffaele Scientific Institute, Milan, Italy
}

\begin{abstract}
Aim. Pancreatic adenocarcinoma is a lifethreatening disease with a rising frequency and the fourth leading cause of cancer death. This review aimed to assess the impact of postoperative radiotherapy through a meta-analysis of prospective randomized studies. Materials and Methods: Six studies met the inclusion criteria and were analyzed to calculate the cumulative risk of death (hazard ratio) in patients affected by pancreatic cancer treated with or without radiotherapy. Higgins' index was used to determine heterogeneity in betweenstudy variability and, subsequently, the random-effects model was applied according to DerSimonian and Laird. Results: Eight hundred and thirty-seven patients were analyzed (418 in the control arm and 419 in the treatment one), the hazard ratio for death after randomization was $0.92(p=0.560,95 \%$ confidence interval=0.70-1.22). When scrutinizing these studies, only one out of six showed a statistically significant benefit due to the addition of radiotherapy in the postoperative setting.
\end{abstract}

This article is freely accessible online.

*These Authors contributed equally to this study.

Correspondence to: Francesco Pasqualetti, MD, Ph.D., Radiation Oncology, Department of Oncology, Azienda Ospedaliero Universitaria Pisana, Via Roma 67, 56123, Pisa, Italy. E-mail: francesco.pasqualetti@oncology.ox.ac.uk; francep24@hotmail.com

Key Words: Pancreatic cancer, radiotherapy, adjuvant radiotherapy, meta-analysis, biomarkers, review.
Conclusion: We conclude that the use of adjuvant radiotherapy is not beneficial in treating all patients affected by pancreatic cancer but only for a subset of cases with potential residual local disease.

Pancreatic cancer is expected to become the second cause of cancer-related death in the next decade; due to its aggressiveness and the early onset of distant metastases, it holds a poor prognosis, and no more than $7 \%$ of all patients survive 5 years following diagnosis (1-5). Despite the latest advances in cancer treatment, surgery still represents the only strategy with curative intent; but even after resection, the 5-year survival rate for all resected patients ranges between $14 \%$ and $27 \%$ (6-9).

Since the 1980 s, the role of radiotherapy in pancreatic cancer has been investigated through prospective phase 3 trials with controversial findings $(10,11)$. While some studies showed a limited benefit using radiotherapy after surgery, other experiences did not indicate any benefit or reported a detrimental effect $(10,11)$. Currently, despite considerable efforts, the clinical impact of adjuvant radiotherapy in patients with pancreatic cancer is still not clear. Furthermore, considering that several clinical trials were carried out more than 30 years ago, new clinical studies with state-of-the-art technology are required to assess the real impact of adjuvant radiotherapy in this setting (12). However, two more major issues must be addressed before planning further studies: the role of the persistence of cancer cells and the selection of patients suitable for postoperative 


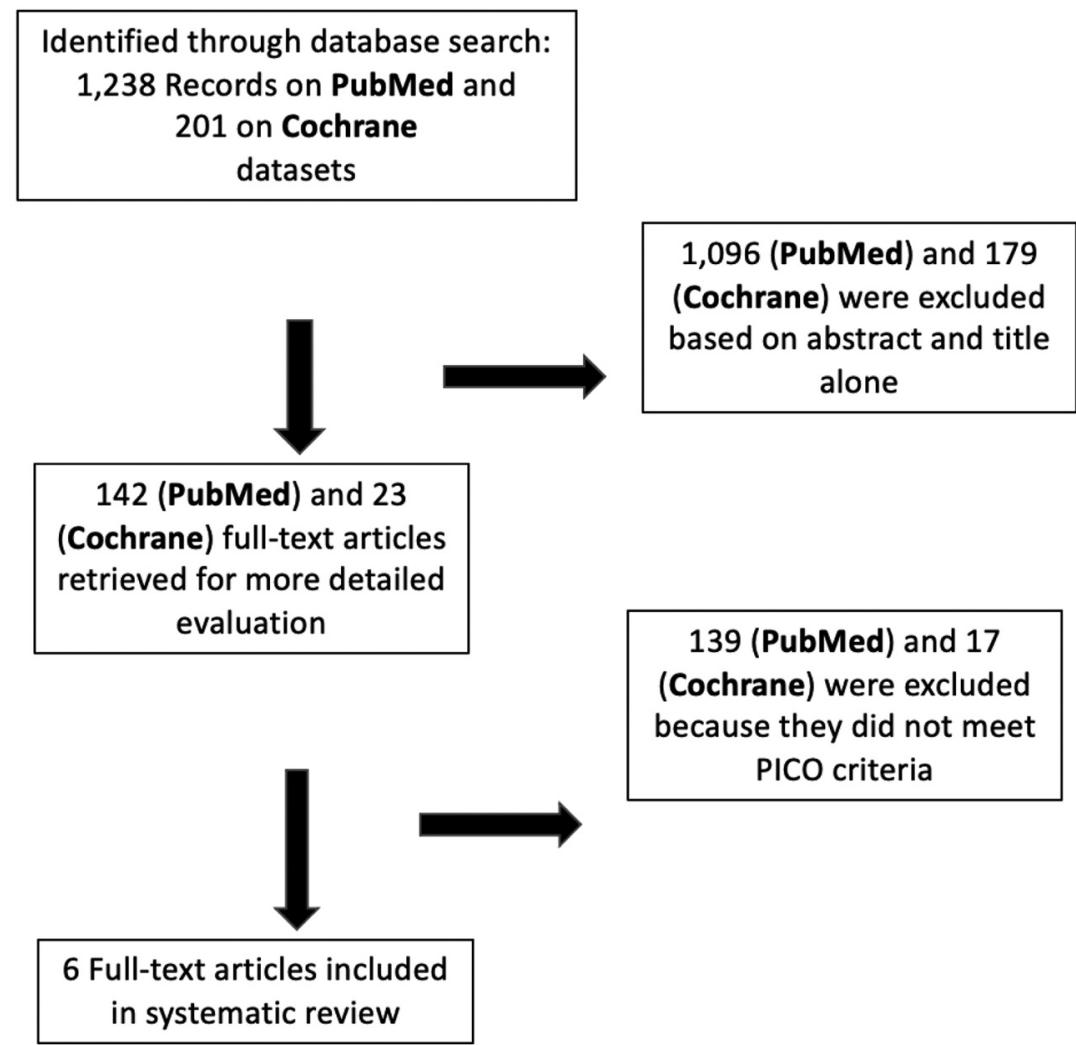

Figure 1. Article retrieval strategy. PICO: Population, Intervention, Comparator and Outcome.

radiotherapy by recognizing the pattern of failure after surgery. The identification of potential biomarkers is desirable to identifying sites of the first recurrence; this may allow physicians to select patients through the probability of relapse locally or systemically, further reducing radiotherapy failures.

In the present article, we focused on the assessment of therapeutic relevance of postoperative radiotherapy by discussing the main limitations of previously published studies.

\section{Materials and Methods}

Literature search and data collection for the meta-analysis. The Population, Intervention, Comparator and Outcome (PICO) framework was used to perform the present analysis (13). The impact of postoperative radiotherapy in patients with pancreatic adenocarcinoma treated through randomized studies represented the research question. Patients not treated with postoperative radiotherapy but with simple follow-up or systemic therapy comprised the control group. The outcomes we considered were overall survival (OS) and, whenever reported, the pattern of failure. A comprehensive literature search of PubMed and Cochrane datasets was conducted for randomized clinical trials comparing radiotherapy with no radiotherapy (with or without chemotherapy) and published from January 1980 until December 2020. The following Medical Subject Headings term was used as a key word: "pancreatic cancer adjuvant radiotherapy". Preferred Reporting Items for Systematic Reviews and Meta-analyses guidelines were adopted (14). The research process is reported in Figure 1. Studies that did not meet the PICO criteria were excluded. From each study, we collected the number of treated patients, concomitant therapy and the dose of radiotherapy, OS, hazard ratio (HR), p-value, nodal and margin status, and pattern of the first recurrence, if reported. Data were systematically reviewed for patients treated with radiotherapy, and patients treated with other postoperative therapies (chemotherapy or follow-up).

To assess the heterogeneity of the data, the Higgins' index (I2) was used (15) and, subsequently, the random-effects model according to DerSimonian and Laird was applied (I2 was greater than $50 \%)(15,16)$. The graphical representation of the metaanalysis was performed using a Forest plot. The bias was analyzed by meta-regression and funnel plot followed by Egger's linear regression test (17). The level of acceptable significance was set to 0.05. Statistical analyses were performed with ProMeta version 2 (Internovi, Cesena, Italy).

Systemic review and meta-analysis. Six studies met our inclusion criteria and were analyzed to calculate the cumulative risk of death (HR) in patients affected by pancreatic cancer treated with or without radiotherapy $(10,11,18-21)$. Radiotherapy was delivered using two opposite fields or conformal 3D techniques. In order to 
Table I. Summary of studies included in the systematic review.

\begin{tabular}{|c|c|c|c|c|c|c|c|c|c|}
\hline $\begin{array}{l}\text { Author } \\
\text { (ref) }\end{array}$ & $\begin{array}{l}\text { No. of } \\
\text { patients } \\
\text { (accrual) }\end{array}$ & $\begin{array}{l}\text { RT dose, } \\
\text { Gy }\end{array}$ & $\begin{array}{l}\text { Regimens } \\
\text { (no. of } \\
\text { patients) }\end{array}$ & $\begin{array}{c}\mathrm{N} \\
\text { Status }\end{array}$ & $\begin{array}{c}\mathrm{R} 1 \\
\text { Status }\end{array}$ & $\begin{array}{l}\text { Median OS, } \\
\text { months }\end{array}$ & $p$-Value & $\operatorname{HR}(95 \% \mathrm{CI})$ & $\begin{array}{l}\text { Pattern of failure } \\
\text { (local only) }\end{array}$ \\
\hline $\begin{array}{l}\text { Kalser and } \\
\text { Ellenberg, } \\
1985(10)\end{array}$ & $43(1975-1982)$ & $40 / 20$ fr* & Observation (22) & $28 \%$ & 0 & 20 & 0.03 & $0.521(0.271-1.003)$ & \\
\hline $\begin{array}{l}\text { Klinkenbij1 } \\
\text { et al., } \\
1999(18)\end{array}$ & 87 (1987-1995) & $40 / 20$ fr* & $\begin{array}{l}\text { Observation (41) } \\
\text { CTRT (46) }\end{array}$ & $\begin{array}{l}56 \% \\
47 \%\end{array}$ & $\begin{array}{l}75 \% \\
81 \%\end{array}$ & $\begin{array}{l}12.6 \\
17.1\end{array}$ & 0.099 & $0.80(0.6-1.1)$ & $\begin{array}{l}15 \% \\
15 \%\end{array}$ \\
\hline $\begin{array}{l}\text { Neoptolemos } \\
\text { et al., } 2004 \\
\text { (11) }\end{array}$ & 289 (1994-2000) & $20 / 10 \mathrm{fr}$ & $\begin{array}{c}\text { CT or } \\
\text { observation }(145) \\
\text { RT +/- CT (144) }\end{array}$ & $\begin{array}{l}54 \% \\
53 \%\end{array}$ & $\begin{array}{l}19 \% \\
16 \%\end{array}$ & $\begin{array}{l}15.9 \\
17.9\end{array}$ & 0.05 & $1.28(0.99-1.66)$ & $35 \%$ \\
\hline $\begin{array}{l}\text { Smeenk } \\
\text { et al., } 2007 \\
\text { (20) }\end{array}$ & 218 (1987-1995) & $40 / 20 \mathrm{fr}^{*}$ & $\begin{array}{l}\text { Observation (108) } \\
\text { CTRT (110) }\end{array}$ & $\begin{array}{l}41 \% \\
37 \%\end{array}$ & $\begin{array}{l}22 \% \\
20 \%\end{array}$ & $\begin{array}{l}19.2 \\
21.6\end{array}$ & 0.540 & $0.91(0.68-1.23)$ & $\begin{array}{l}20 \% \\
21 \%\end{array}$ \\
\hline $\begin{array}{l}\text { Van Laethem } \\
\text { et al., } 2010 \\
(21)\end{array}$ & 90 (2004-2007) & $50.4 / 28 \mathrm{fr}$ & $\begin{array}{l}\text { CT alone (45) } \\
\text { CT+CTRT (45) }\end{array}$ & $\begin{array}{l}70 \% \\
69 \%\end{array}$ & $\begin{array}{l}0 \\
0\end{array}$ & $\begin{array}{l}24 \\
24\end{array}$ & & $1.197(0.630-1.569)$ & $\begin{array}{l}24 \% \\
11 \%\end{array}$ \\
\hline $\begin{array}{l}\text { Schmidt } \\
\text { et al., } 2012 \\
\text { (19) }\end{array}$ & $110(2004-2007)$ & $50.4 / 28 \mathrm{fr}$ & $\begin{array}{c}\text { CT (57) } \\
\text { CTRT+ INF } \alpha(53)\end{array}$ & $\begin{array}{l}79 \% \\
79 \%\end{array}$ & $\begin{array}{l}34 \% \\
45 \%\end{array}$ & $\begin{array}{l}28.5 \\
32.1\end{array}$ & 0.99 & $1.04(0.66-1.53)$ & \\
\hline
\end{tabular}

CI: Confidence intervaI; CT: Chemotherapy; CTRT: chemo-radiotherapy; fr: fraction; HR: hazard ratio; INF: interferon; N.A.: not available; OS: overall survival. *Split course was planned during radiotherapy.

reduce gastrointestinal toxicity, four studies planned to deliver 40 Gy in 20 fractions with a 2-week split course during treatment. In two studies [Kalser and Ellenberg (10) and Klinkebijil et al. (18)], the total dose of radiotherapy was 20 Gy in 10 fractions and 50.4 Gy in 28 fractions, respectively $(10,18)$.

Concomitant chemotherapy was administered in all studies. 5Fluorouracil (5-FU), a nucleoside metabolism inhibitor, was adopted by Kalser and Ellenberg (10), Klinkebijil et al. (18), Neoptolemo et al. (11) and Smeenk et al. (20), whereas Van Laethem et al. (21) used gemcitabine, which inhibits DNA synthesis. The group of Schmidt (19) opted for a combination of 5-FU, cisplatin, which acts by inducing DNA damage, and interferon $\alpha-2 b$ (IFN-2b), a cytokine that directly regulates transcription of genes involved in the immune response. The pattern of isolated local failure was reported in five studies. Van Laethem et al. reported better local control in patients treated with chemoradiation respect to control arm, $24 \%$ versus $11 \%$, respectively (21). All the studies enrolled patients with positive lymph nodes. Of note, Van Laethem et al. and Kalser and Ellenberg did not enroll patients with positive surgical margins.

\section{Results}

The cases of 837 patients were analyzed: 419 were treated with postoperative radio- or radio-chemotherapy, whereas 418 were proposed observation or chemotherapy only. The HR for death after randomization obtained by the meta-analysis was 0.92 , with an associated $p$-value of 0.560 (95\% confidence interval $=0.70-1.22$ ). The summary of studies included in the systematic review is reported in Table I. Only the study performed by Kalser and Ellenberg (10) showed a statistically significant benefit due to the addition of radiotherapy in the postoperative setting; the other five did not demonstrate any additional benefit. The Forest plot calculated with the randomeffects model $\left(\mathrm{I}^{2}=61.76\right)$ underlined the lack of efficacy of adjuvant radiotherapy. Moreover, meta-regression (randomeffects model) and Funnel plot were performed to exclude both influences related to the development of new technologies and publication biases (Figure 2, Figure 3 and Figure 4).

\section{Discussion}

Pancreatic cancer is becoming increasingly common in developed countries, and further prospective studies are necessary to develop and evaluate more targeted, personalized therapies. Owing to several pieces of clinical evidence, postoperative radiotherapy was introduced into the clinical practice of treating several solid tumor types over the past decades. Overall, the significant limits encountered in setting up clinical studies of adjuvant therapy with an 


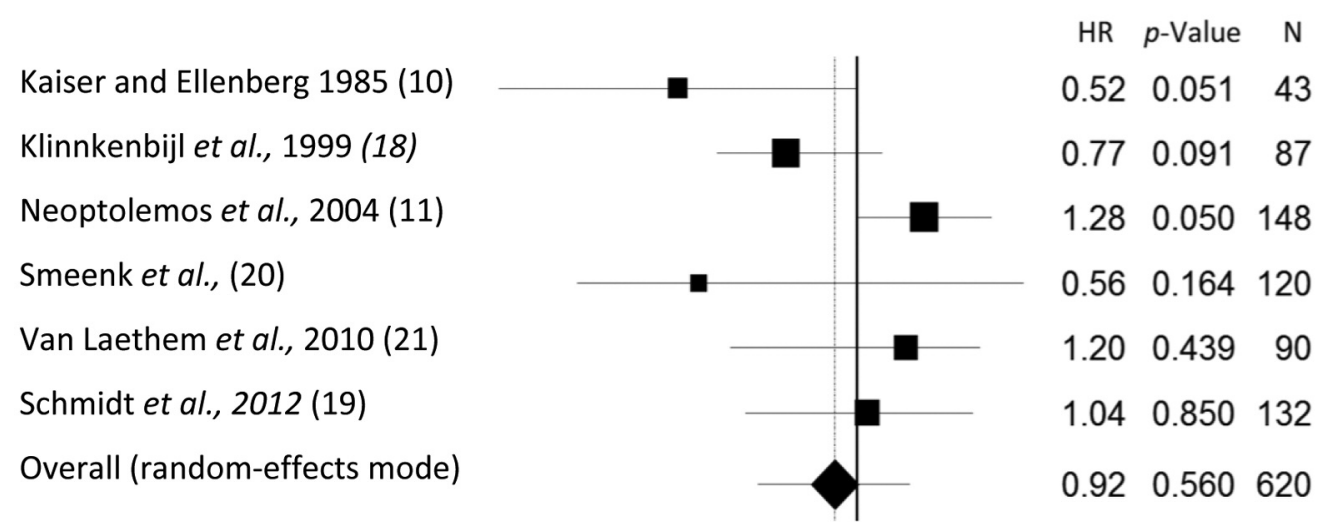

Figure 2. Forest plot calculated with random-effects model relating the influence of therapy (no radiotherapy (=0) vs. radiotherapy (=1)) on overall survival. HR: Hazard ratio.

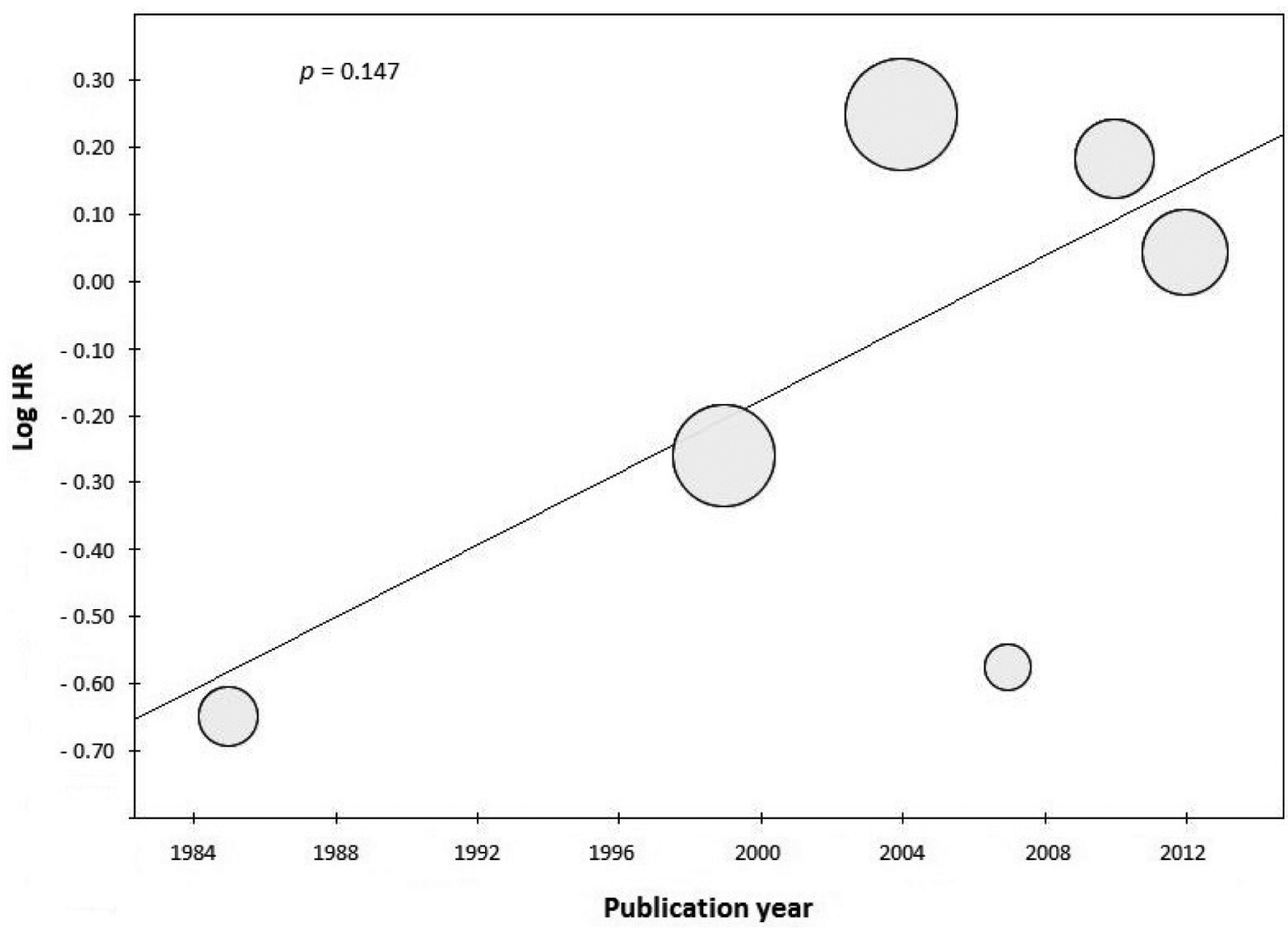

Figure 3. Meta-regression (random-effects model) to exclude correlation between publications year and log hazard ratio (HR).

adequate dose of ionizing radiation in patients diagnosed with pancreatic cancer are related to the anatomy of the pancreas, therefore associated with organ motion due to breathing, contact with the gastrointestinal tract and severe clinical sequelae of surgery. On this basis, we carried out the present meta-analysis to query the impact of postoperative radiotherapy in patients with pancreatic adenocarcinoma and gave a critical interpretation of almost all the selected 


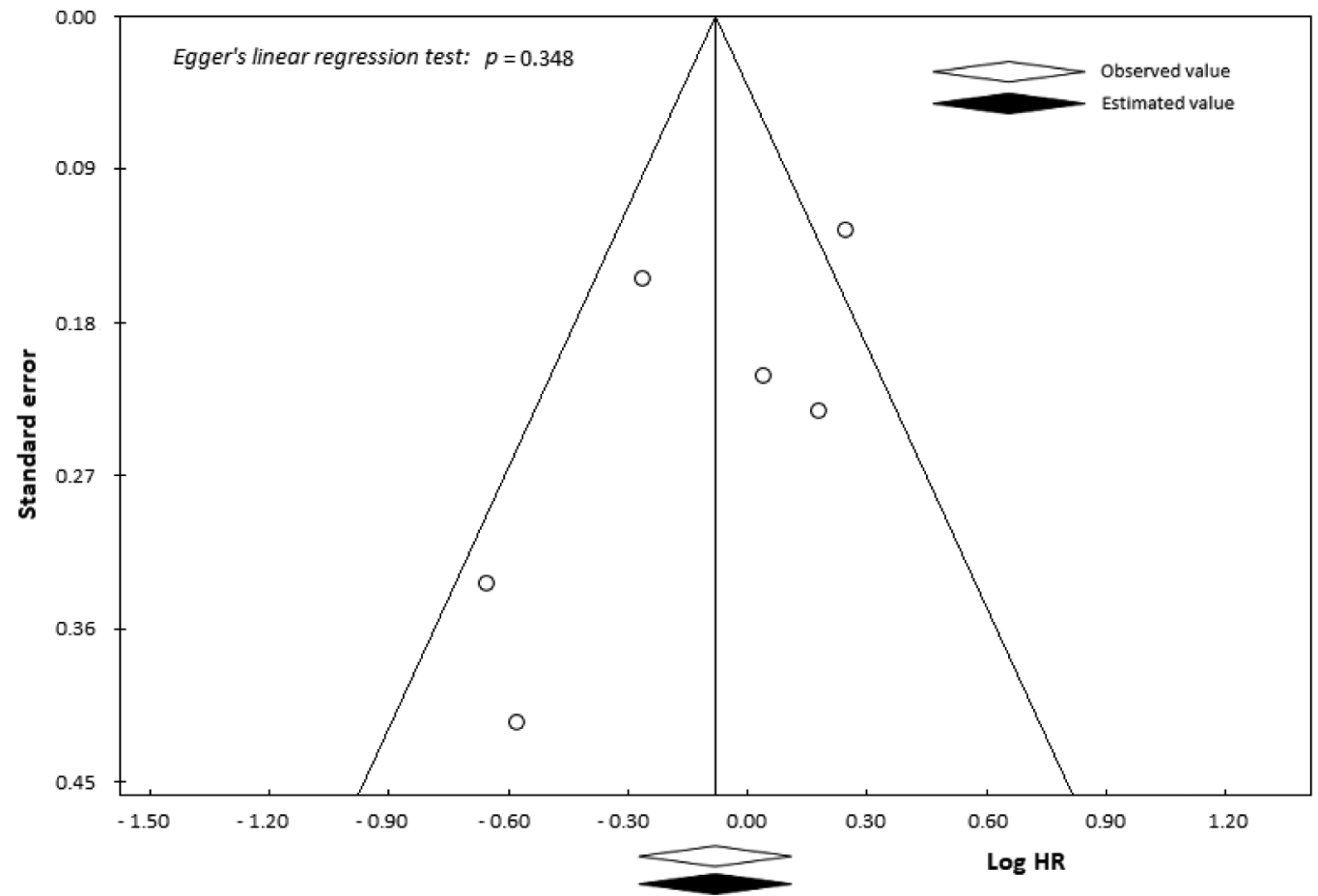

Figure 4. Funnel plot to assess publication bias.

studies' poor results, focusing our attention on the causes of failure or success of each study.

We found six randomized studies that met our inclusion criteria, enrolling patients over a long period, between 1987 and 2007 (we did not find more recent studies). A major deficit in those experiences is the lack of use of modern techniques, such as intensity-modulated radiotherapy or image-guided radiotherapy, to overcome limitations related to the inclusion of large parts of gastrointestinal tract within the treatment fields. Therefore, the total dose of ionizing radiations was much lower than the dose delivered in the adjuvant setting for other malignancies.

In the mid-1980s, the Gastrointestinal Tumor Study Group (GITSG) planned the first randomized trial to demonstrate a survival benefit of adjuvant chemoradiation in patients who underwent surgery for pancreatic cancer (10). The GITSG trial randomized 43 patients between the late 1970s and early 1980s. Despite the low total dose of ionizing radiation, 40 Gy in 20 fractions, were delivered using a 2D technique with a split course during treatment. Limitations included the small sample size, the lack of accurate restaging after surgery and the length of the accrual. This study reported a survival benefit using radiotherapy. Patients who received adjuvant radio-chemotherapy had longer median OS (20 versus 11 months, $p=0.03$ ).
The promising results published by the GITSG prompted the establishment of several clinical trials, conducted in both North America and Europe, with the aim of assessing the role of adjuvant radiotherapy. The European Organization for Research and Treatment of Cancer randomly assigned 218 patients who underwent surgery for pancreatic cancer to receive postoperative radio-chemotherapy (5-FU plus $40 \mathrm{~Gy}$ ) or observation (20). The improvement recorded in OS was not statistically significant (2-year survival rate: $23 \%$ versus $37 \%, p=0.099)$. Sites of first recurrence were the same in the two arms, with local, distant and both being recorded in $20 \%$, $48 \%$ and $29 \%$ of patients treated with radiotherapy and in $30 \%$ of patients in the observation group. The dose of radiotherapy was the same adopted by the study by Kalser and Ellenberg, 40 Gy in 20 fractions with a split course (10). Despite the lack of benefit in patients overall, the authors reported an advantage in OS by treating lymph node-negative patients $(p=0.023)$. This result was confirmed by a multivariate analysis performed by Winter et al. The study analyzed operated pancreas cancer and observed that the presence of regional lymph node metastases was the only factor associated with the development of distant metastases (odds ratio $=4.7, p=0.02$ (22).

From 1994 until 2000, the European Study Group for Pancreatic Cancer 1 trial (ESPAC-1) investigated the role of 
adjuvant therapy in a $2 \times 2$ factorial design, where the relative benefit of adjuvant chemotherapy and complete resection followed by radiotherapy were addressed (11). The administration of adjuvant chemotherapy conferred a statistically significant advantage in OS, on the other hand, adjuvant radio-chemotherapy had a detrimental effect (median OS durations were 17.9 and 15.9 months, respectively; $p=0.05)$. The authors did not report the pattern of failure for each arm; however, the cumulative local, distant, and primary recurrence rates were $35 \%, 53 \%$ and $27 \%$, respectively (11).

In 1999, Klinkenbiji et al. published the results of a randomized trial enrolling patients after curative resection of cancer of the pancreas and periampullary region (18). The authors randomized 218 patients to receive adjuvant radiochemotherapy with 5-FU or to observation. Among these patients, 87 had pancreatic cancer (46 in the treatment arm, 41 in the control arm). Radiotherapy was delivered with 2D technique, 40 Gy in 20 fractions with a split course. This population-based study did not report any improvement in OS due to radio-chemotherapy. Moreover, the analysis of local control was not in favor of treated patients and the number of isolated local recurrences was equal in both arms.

Different results on local control were found by the study of Van Laethem et al., which enrolled patients in the early 2000s. This phase 2 trial planned to explore the feasibility and tolerability of gemcitabine-based radio-chemotherapy regimen and not its impact on OS. Consequently, this study did not hold the statistical power to assess the difference in OS (21). However, the clinical trial adopted a higher dose of ionizing radiation, $50.4 \mathrm{~Gy}$ in 28 fractions, and reported fewer isolated local failures in the treatment arm $(11 \%$ versus $24.4 \%$ ) (21).

In 2012, Schmidt et al. analyzed the results of an openlabel, multicenter, randomized phase 3 trial of adjuvant radiochemotherapy in addition to IFN-2b and cisplatin versus 5FU and folinic acid for patients who underwent resection of pancreatic adenocarcinoma (19). The study attempted to investigate the impact of concurrent radiotherapy plus 5-FU and IFN-2b in this setting. The research group concluded that the combination of 5-FU, cisplatin and IFN-2b in combination with radiotherapy did not improve the survival rate compared to 5-FU monotherapy.

In over 20 years, randomized trials on adjuvant radiotherapy in pancreatic cancer experienced a series of modifications, including the introduction of new techniques of radiotherapy and the improvement of control arm. The absence of an active treatment in the control arm could have contributed to obtaining a beneficial effect in the radiotherapy arm of the study by Kalser and Ellenberg (10) In this specific trial, the median OS recorded in the control arm (follow-up) was 11 months only; otherwise, median OS of the control arms in the data collected by Van Laethem et al. (21) and Schmidt et al. (19) were 24 and 28.5 months, respectively.
The significant limitation of the first four trials of the present review is that the dose of radiotherapy delivered to the surgical bed was not enough to prevent disease recurrence and affect patients' survival. Despite data on OS still being disappointing, the study that delivered $50.4 \mathrm{~Gy}$ using a 3D technique showed at least improved local control (21). On this basis, several authors asserted that as a direct effect of the technical advances in radiotherapy planning and delivering, both local control and OS would be prolonged in upcoming years $(23,24)$. They also suggested to eventually re-evaluate all published literature considering the latest technology. However, as the results of the ESPAC-1 trial showed a poor or even detrimental effect of radiotherapy in the adjuvant setting, an increasing number of researchers no longer consider radio or radio-chemotherapy a good adjuvant therapy to be studied in their trials. For this reason, number of clinical studies with state-of-the-art radiotherapy techniques is limited $(4,24)$.

After considering that radiotherapy techniques used in many of the previously described studies are frequently outdated together with low dosages, we also considered two additional topics. Firstly, many patients who undergo surgery for pancreatic cancer are likely to receive an early salvage form of radiotherapy instead of adjuvant radiotherapy (which, for definition, implies the absence of recordable disease). This is due to a persistent undetectable disease, or an early tumor recurrence soon after surgery. For example, worst prognosis is often observed in patients with both positive surgical margins and lymph node metastases (25, 26). Therefore, to avoid treating patients with salvage therapy, an accurate tumor restaging after surgery is mandatory before considering adjuvant therapy. Secondly, considering that adjuvant radio or radio-chemotherapy intends to prolong OS by improving local control, the study of the pattern of first recurrence following curative surgery plays a crucial role in assessing the failure of most randomized trials. In the trial by Smeenk et al., the first recurrence pattern (local failure without distant metastasis) was recorded only in $20 \%$ of patients treated with radiochemotherapy and in $21 \%$ of patients in the control arm (20). This indicates that almost $80 \%$ of patients received local treatment when the disease was already systemic. The ESPAC-1 study reported analogous results, showing a similar pattern of failure. In this trial, more than $65 \%$ of patients developed systemic disease at the time of the first recurrence.

In 2018, Groot et al. described the pattern of failure for 1,325 patients who underwent surgery for resection of pancreatic adenocarcinoma between 2000 and 2013 (27). The most common manifestation of disease recurrence was observed in more than one site. Multiple sites, liver-only, lungonly and local-only were found in $34.4 \%, 25.1 \%, 14 \%$ and $23.9 \%$, respectively. Patients with multiple-site or liver-only 
recurrence had a limited disease-free and median survival compared to the patients that did not. Sperti et al. (28) and Suenaga et al. (29) reported analogous data, confirming the relevance of the pattern of failure. Further analysis revealed that among the operated patients, those who relapsed earlier had a systemic pattern of failure and relatively limited survival. Moreover, lung- and local-only recurrence were associated with prolonged OS compared to other failure patterns. The favorable prognosis associated with isolated local recurrence might be due to two factors: (i) a less aggressive tumor phenotype and (ii) residual cancer cells situated within the surgical bed.

These findings shed further light for the RTOG 0848 phase 3 study, where patients without disease progression were randomized to receive or not adjuvant radiotherapy several months after surgery. The long period elapse following surgery can help to identify and exclude from randomization patients who experienced systemic recurrence before the start of radiotherapy (4). Considering the small sample size of the GITSG trial, a slight displacement of three to four patients with residual subclinical pancreatic cancer cells localized in the surgical bed or locoregional lymph nodes into the radiotherapy arms might explain the positive results obtained in this study (10). The greater sample size adopted in the other trials selected for the present analysis limited this bias. Based on the previously discussed clinical trials and on the heterogenous nature of pancreatic cancer, research efforts must focus on identifying the best adjuvant therapy for patients with pancreatic adenocarcinoma, taking into consideration the characterization of the behavior of recurrent disease.

\section{Conclusion}

The study of adjuvant radiotherapy in patients with pancreatic adenocarcinoma may achieve one of the first crossfertilization efforts between the development of new technologies and the identification of high-risk patients with isolated localized recurrence through translational research. Future studies need to tailor adjuvant radiotherapy based on biological features and highly accurate restaging of pancreatic cancer, as well as implementing state-of-the art radiotherapy.

\section{Conflicts of Interest}

The Authors declare that they have no conflicts of interest. This research did not receive any specific grant from funding agencies in the public, commercial or not-for-profit sectors.

\section{Authors' Contributions}

FP, AS, FP, MF, SZ, GG contributed to setting up the present study. LL, SM, AG, TF, and NG contributed to data retrieval. RM, NC and FP performed data analysis. FP and MF wrote the article.

\section{References}

1 Hidalgo M, Cascinu S, Kleeff J, Labianca R, Löhr JM, Neoptolemos J, Real FX, Van Laethem JL and Heinemann V: Addressing the challenges of pancreatic cancer: future directions for improving outcomes. Pancreatology 15(1): 8-18, 2015. PMID: 25547205. DOI: 10.1016/j.pan.2014.10.001

2 Smittenaar CR, Petersen KA, Stewart K and Moitt N: Cancer incidence and mortality projections in the UK until 2035. Br J Cancer 115(9): 1147-1155, 2016. PMID: 27727232. DOI: 10.1038/bjc.2016.304

3 Chang JS, Chen LT, Shan YS, Chu PY, Tsai CR and Tsai HJ: The incidence and survival of pancreatic cancer by histology, including rare subtypes: a nation-wide cancer registry-based study from Taiwan. Cancer Med 7(11): 5775-5788, 2018. PMID: 30264519. DOI: 10.1002/cam4.1795

4 Abrams RA, Winter KA, Safran H, Goodman KA, Regine WF, Berger AC, Gillin MT, Philip PA, Lowy AM, Wu A, DiPetrillo TA, Corn BW, Seaward SA, Haddock MG, Song S, Jiang Y, Fisher BJ, Katz AW, Mehta S, Willett CG and Crane CH: Results of the NRG oncology/RTOG 0848 adjuvant chemotherapy questionerlotinib+gemcitabine for resected cancer of the pancreatic head: A phase II randomized clinical trial. Am J Clin Oncol 43(3): 173-179, 2020. PMID: 31985516. DOI: 10.1097/COC.0000000000000633

5 Miller KD, Siegel RL, Lin CC, Mariotto AB, Kramer JL, Rowland JH, Stein KD, Alteri R and Jemal A: Cancer treatment and survivorship statistics, 2016. CA Cancer J Clin 66(4): 271289, 2016. PMID: 27253694. DOI: 10.3322/caac.21349

6 Kleeff J, Korc M, Apte M, La Vecchia C, Johnson CD, Biankin AV, Neale RE, Tempero M, Tuveson DA, Hruban RH and Neoptolemos JP: Pancreatic cancer. Nat Rev Dis Primers 2: 16022, 2016. PMID: 27158978. DOI: 10.1038/nrdp.2016.22

7 Sainato A, Montrone S, Pasqualetti F, Coppola M, Cernusco NLV, Panichi M, Gonnelli A, Vasile E, Morganti R, Falcone A, Boggi $U$ and Paiar F: Adjuvant chemoradiotherapy (gemcitabine-based) in pancreatic adenocarcinoma: the Pisa University experience. Tumori 103(6): 577-582, 2017. PMID: 28708229. DOI: $10.5301 / \mathrm{tj} .5000664$

8 Sener SF, Fremgen A, Menck HR and Winchester DP: Pancreatic cancer: a report of treatment and survival trends for 100,313 patients diagnosed from 1985-1995, using the National Cancer Database. J Am Coll Surg 189(1): 1-7, 1999. PMID: 10401733. DOI: 10.1016/s1072-7515(99)00075-7

9 Staley CA, Lee JE, Cleary KR, Abbruzzese JL, Fenoglio CJ, Rich TA and Evans DB: Preoperative chemoradiation, pancreaticoduodenectomy, and intraoperative radiation therapy for adenocarcinoma of the pancreatic head. Am J Surg 171(1): 118-24; discussion 124-5, 1996. PMID: 8554125. DOI: 10.1016/S0002-9610(99)80085-3

$10 \mathrm{Kalser} \mathrm{MH}$ and Ellenberg SS: Pancreatic cancer. Adjuvant combined radiation and chemotherapy following curative resection. Arch Surg 120(8): 899-903, 1985. PMID: 4015380. DOI: $10.1001 /$ archsurg.1985.01390320023003

11 Neoptolemos JP, Stocken DD, Friess H, Bassi C, Dunn JA, Hickey H, Beger H, Fernandez-Cruz L, Dervenis C, Lacaine F, Falconi M, Pederzoli P, Pap A, Spooner D, Kerr DJ, Büchler MW and European Study Group for Pancreatic Cancer: A randomized trial of chemoradiotherapy and chemotherapy after resection of pancreatic cancer. N Engl J Med 350(12): 12001210, 2004. PMID: 15028824. DOI: 10.1056/NEJMoa032295 
12 Palta M, Godfrey D, Goodman KA, Hoffe S, Dawson LA, Dessert D, Hall WA, Herman JM, Khorana AA, Merchant N, Parekh A, Patton C, Pepek JM, Salama JK, Tuli R and Koong AC: Radiation therapy for pancreatic cancer: Executive summary of an ASTRO clinical practice guideline. Pract Radiat Oncol 9(5): 322-332, 2019. PMID: 31474330 . DOI: 10.1016/j.prro.2019.06.016

13 Richardson WS, Wilson MC, Nishikawa J and Hayward RS: The well-built clinical question: a key to evidence-based decisions. ACP J Club 123(3): A12-A13, 1995. PMID: 7582737.

14 Liberati A, Altman DG, Tetzlaff J, Mulrow C, Gøtzsche PC, Ioannidis JP, Clarke M, Devereaux PJ, Kleijnen J and Moher D: The PRISMA statement for reporting systematic reviews and meta-analyses of studies that evaluate health care interventions: explanation and elaboration. PLoS Med 6(7): e1000100, 2009. PMID: 19621070. DOI: 10.1371/journal.pmed.1000100

15 Higgins JP and Thompson SG: Quantifying heterogeneity in a meta-analysis. Stat Med 21(11): 1539-1558, 2002. PMID: 12111919. DOI: $10.1002 / \mathrm{sim} .1186$

16 DerSimonian R and Laird N: Meta-analysis in clinical trials. Control Clin Trials 7(3): 177-188, 1986. PMID: 3802833. DOI: 10.1016/0197-2456(86)90046-2

17 Sterne JA and Egger M: Funnel plots for detecting bias in metaanalysis: guidelines on choice of axis. J Clin Epidemiol 54(10): 1046-1055, 2001. PMID: 11576817. DOI: 10.1016/s08954356(01)00377-8

18 Klinkenbijl JH, Jeekel J, Sahmoud T, van Pel R, Couvreur ML, Veenhof CH, Arnaud JP, Gonzalez DG, de Wit LT, Hennipman A and Wils J: Adjuvant radiotherapy and 5-fluorouracil after curative resection of cancer of the pancreas and periampullary region: phase III trial of the EORTC gastrointestinal tract cancer cooperative group. Ann Surg 230(6): 776-82; discussion 782-4, 1999. PMID: 10615932. DOI: 10.1097/00000658-19991200000006

19 Schmidt J, Abel U, Debus J, Harig S, Hoffmann K, Herrmann T, Bartsch D, Klein J, Mansmann U, Jäger D, Capussotti L, Kunz R and Büchler MW: Open-label, multicenter, randomized phase III trial of adjuvant chemoradiation plus interferon Alfa$2 \mathrm{~b}$ versus fluorouracil and folinic acid for patients with resected pancreatic adenocarcinoma. J Clin Oncol 30(33): 4077-4083, 2012. PMID: 23008325. DOI: 10.1200/JCO.2011.38.2960

20 Smeenk HG, Erdmann J, van Dekken H, van Marion R, Hop WC, Jeekel J and van Eijck CH: Long-term survival after radical resection for pancreatic head and ampullary cancer: a potential role for the EGF-R. Dig Surg 24(1): 38-45, 2007. PMID: 17369680. DOI: $10.1159 / 000100917$

21 Van Laethem JL, Hammel P, Mornex F, Azria D, Van Tienhoven G, Vergauwe P, Peeters M, Polus M, Praet M, Mauer M, Collette L, Budach V, Lutz M, Van Cutsem E and Haustermans K: Adjuvant gemcitabine alone versus gemcitabine-based chemoradiotherapy after curative resection for pancreatic cancer: a randomized EORTC-40013-22012/FFCD-9203/GERCOR phase II study. J Clin Oncol 28(29): 4450-4456, 2010. PMID: 20837948. DOI: $10.1200 / J C O .2010 .30 .3446$
22 Winter JM, Tang LH, Klimstra DS, Liu W, Linkov I, Brennan MF, D'Angelica MI, DeMatteo RP, Fong Y, Jarnagin WR, O'reilly EM and Allen PJ: Failure patterns in resected pancreas adenocarcinoma: lack of predicted benefit to SMAD4 expression. Ann Surg 258(2): 331-335, 2013. PMID: 23360922. DOI: $10.1097 /$ SLA.0b013e31827fe9ce

23 Venkatesulu BP, Hsieh CE, Sanders KL and Krishnan S: Recent advances in radiation therapy of pancreatic cancer. F1000Res 7: F1000 Faculty Rev-1931, 2018. PMID: 30613390. DOI: 10.12688/f1000research.16272.1

24 Bouchart C, Navez J, Closset J, Hendlisz A, Van Gestel D, Moretti L and Van Laethem JL: Novel strategies using modern radiotherapy to improve pancreatic cancer outcomes: toward a new standard? Ther Adv Med Oncol 12: 1758835920936093 , 2020. PMID: 32684987. DOI: 10.1177/1758835920936093

25 Richter A, Niedergethmann M, Sturm JW, Lorenz D, Post S and Trede M: Long-term results of partial pancreaticoduodenectomy for ductal adenocarcinoma of the pancreatic head: 25-year experience. World J Surg 27(3): 324-329, 2003. PMID: 12607060. DOI: 10.1007/s00268-002-6659-z

26 Sohn TA, Yeo CJ, Cameron JL, Koniaris L, Kaushal S, Abrams RA, Sauter PK, Coleman J, Hruban RH and Lillemoe KD: Resected adenocarcinoma of the pancreas-616 patients: results, outcomes, and prognostic indicators. J Gastrointest Surg 4(6): 567-579, 2000. PMID: 11307091. DOI: 10.1016/s1091-255x(00) 80105-5

27 Groot VP, Gemenetzis G, Blair AB, Ding D, Javed AA, Burkhart RA, Yu J, Borel Rinkes IH, Molenaar IQ, Cameron JL, Fishman EK, Hruban RH, Weiss MJ, Wolfgang CL and He J: Implications of the pattern of disease recurrence on survival following pancreatectomy for pancreatic ductal adenocarcinoma. Ann Surg Oncol 25(8): 2475-2483, 2018. PMID: 29948425. DOI: 10.1245/s10434-018-6558-7

28 Sperti C, Pasquali C, Piccoli A and Pedrazzoli S: Recurrence after resection for ductal adenocarcinoma of the pancreas. World J Surg 21(2): 195-200, 1997. PMID: 8995078. DOI: 10.1007/ s002689900215

29 Suenaga M, Fujii T, Kanda M, Takami H, Okumura N, Inokawa Y, Kobayashi D, Tanaka C, Yamada S, Sugimoto H, Nomoto S, Fujiwara M and Kodera Y: Pattern of first recurrent lesions in pancreatic cancer: hepatic relapse is associated with dismal prognosis and portal vein invasion. Hepatogastroenterology 61(134): 1756-1761, 2014. PMID: 25436375. 